\title{
TRASPLANTES RETINIANOS: ESTADO ACTUAL Y SUS PROBLEMAS EN LA APLICACIÓN CLÍNICA
}

\section{UPDATE ON RETINAL TRANSPLANTATION AND ITS CLINICAL LIMITATIONS}

\author{
PINILLA I ${ }^{1}$, CUENCA N ${ }^{2}$
}

Las terapias celular y genética constituyen en la actualidad aproximaciones realistas en el tratamiento de enfermedades neurodegenerativas de la retina.

Los avances en la Genética han proporcionado una nueva visión de la fisiología y patogénesis de determinadas enfermedades retinianas de base genética, y su tratamiento potencial por modificación de los genes afectos. Aunque se han logrado grandes avances en su utilización en modelos animales e incluso se encuentra en fase de experimentación clínica en determinadas patologías como la amaurosis congénita de Leber, la terapia génica no parece ser una opción en enfermos con una importante pérdida visual como resultado de la pérdida de los fotorreceptores o las células del epitelio pigmentario retiniano (EPR), que han ocasionado grandes cambios en los circuitos retinianos $(1,2)$. También es problemática su utilización en patologías con gran cantidad de factores etiopatogénicos, como la Degeneración Macular Asociada a la Edad y es altamente costosa en enfermedades en las que existen y siguen descubriéndose un innumerable número de genes implicados en su patogenia, como la Retinosis Pigmentaria.

La posibilidad de reestablecer visión fue el fundamento del inicio de la investigación en trasplantes retinianos. La realización de trasplantes retinianos a nivel cerebral demostró que el trasplante tenía capacidad de crecimiento axonal con establecimiento de sinapsis y respuestas fisiológicas (3). Con esta base, era fácil pensar que si el trasplante se realizaba a nivel subretiniano podía ser posible que las células emplazadas establecieran nuevas conexiones sinápticas y tuvieran capacidad funcional.
Existen dos aproximaciones diferentes al trasplante retiniano: la primera es limitar la pérdida de fotorreceptores introduciendo células que mantengan a estos primeros funcionales y la segunda opción es reemplazar los fotorreceptores perdidos. Ambas opciones tienen problemas comunes: elegir el tipo celular adecuado, el método de trasplante (células aisladas o tejido íntegro), como minimizar la reacción inflamatoria postoperatoria y la respuesta inmune, el modo de realización del trasplante, optimizar su eficacia y la valoración del éxito postoperatorio.

La elección del tipo celular dependerá de la causa de la pérdida de los fotorreceptores. Si la enfermedad está originada por un defecto en el EPR puede inyectarse este tipo celular $\mathrm{u}$ otras células que mejoren el ambiente químico a nivel del espacio subretiniano. Se han utilizado células de EPR, células pigmentadas de iris o células inmortalizadas logrando mejorar la supervivencia celular consiguiendo además su mantenimiento funcional $(4,5)$. Para la mejoría del ambiente celular se ha utilizado la inyección de factores de crecimiento o neurotrofinas, el trasplante de células secretoras de factores de crecimiento (como las células de Schwann), la inyección intravítrea de células encapsuladas liberadoras de factores neurotróficos, o trasplantes de bastones, que son capaces de producir factores de crecimiento que mejoren la supervivencia de los conos.

Si el defecto es primario de los fotorreceptores se pueden introducir piezas o láminas retinianas. Estas estrategias tienen que tener en cuenta la gran reorganización sináptica que se produce por la muerte

\footnotetext{
1 Servicio de Oftalmología. Hospital Universitario Miguel Servet. Zaragoza. España. Instituto Aragonés de Ciencias de la Salud. E-mail: isabel.pinilla@telefonica.net

2 Departamento de Biotecnología. Facultad de Ciencias. Universidad de Alicante. España.
} 
neuronal $(1,2)$. Su utilidad por tanto, queda limitada a estadios muy precoces de la degeneración.

Las dos preguntas principales que se plantean después de este tratamiento son: ¿puede realmente mantenerse la visión después del trasplante? y ¿cómo funcionan las células inyectadas? Se han recogido pruebas de función y capacidad visual en roedores utilizando tests de comportamiento, electrorretinogramas, curvas de adaptación a la luz, niveles de respuesta en el colículo superior, test del reflejo pupilar... sugiriendo el mantenimiento de función. El modo en que funcionan las células una vez trasplantadas no está claro. Se ha sugerido que las células de EPR o los fotorreceptores inyectados realizan la función de las células defectuosas pero existen pocos trabajos que sean capaces de identificar las células trasplantadas y menos que demuestren la capacidad de fagocitosis del EPR inyectado. Posiblemente mejoren la función de las células existentes.

Aunque el primer trasplante retiniano se realizó hace 60 años, su máximo interés lo adquiere en la década de los 80. Los primeros resultados en animales provocaron un gran entusiasmo. Sin embargo siguen existiendo muchas preguntas todavía por responder. Los primeros trasplantes en humanos se realizaron en la década de los 90, comprobándose su seguridad, sin grandes resultados funcionales. Probablemente la causa de la falta de función sea la realización de los trasplantes en casos muy avanzados de degeneración retiniana, cuando los cambios de las neuronas secundarias son tan importantes que no existe posibilidad de transmisión sináptica por la gran remodelación de los circuitos retinianos.

En la actualidad, la mayoría de los grupos que realizan trasplantes están convencidos que sigue necesitándose más investigación básica para profundizar en el conocimiento sobre los trasplantes y sus resultados, mejorando el ambiente de las células donantes, manipulando químicamente la membrana de Bruch para que las células del EPR puedan unirse a ella, mejorando las estrategias para reemplazar fotorreceptores perdidos modulando la respuesta inmune o ayudando al reestablecimiento de circuitos neuronales, minimizando las respuestas inflamatorias e inmunes,...
Por último hay que considerar otra alternativa terapéutica como es la inyección de células madre pluripotenciales, con capacidad tanto de ayudar a la permanencia celular como de reemplazar fotorreceptores perdidos. Recientemente se han utilizado células madre embrionarias humanas ES o células madre procedentes de la médula ósea que inyectadas en el espacio subretiniano o en el vítreo han mostrado capacidad para diferenciarse en neuronas e integrarse en los circuitos retinianos. Estos resultados abren grandes esperanzas en el tratamiento de patologías retinianas, aunque sigue siendo necesario un incremento de la investigación básica con el fin de conocer los mecanismos involucrados en la diferenciación, integración y funcionalidad de las células trasplantadas.

En resumen, se han hecho grandes avances en el campo de los trasplantes retinianos en las últimas dos décadas. Es necesario tener conocimiento de ello y de otras opciones terapéuticas como la utilización de neurotrofinas o de células madre o de los sistemas protésicos visuales para poder contestar a las preguntas de los pacientes y darles una visión realista de sus expectativas, de las limitaciones actuales y de la continua investigación que se está haciendo en este campo.

\section{BIBLIOGRAFÍA}

1. Cuenca N, Pinilla I, Sauve Y, Lu B, Wang S, Lund RD. Regressive and reactive changes in the connectivity patterns of rod and cone pathways of $\mathrm{P} 23 \mathrm{H}$ transgenic rat retina. Neuroscience 2004; 127: 301-317.

2. Cuenca N, Pinilla I, Sauve Y, Lund R. Changes in synaptic connectivity following progressive photoreceptor degeneration in RCS rats. Eur J Neurosci 2005; 22: $1057-$ 1072.

3. McLoon SC, Lund RD. Specific projections of retina transplanted to rat brain. Exp Brain Res 1980; 40: 273-282.

4. Lund RD, Adamson P, Sauve Y, Keegan DJ, Girman SV, Wang $S$, et al. Subretinal transplantation of genetically modified human cell lines attenuates loss of visual function in dystrophic rats. Proc Natl Acad Sci USA 2001; 98: 9942-9947.

5. Sauve Y, Pinilla I, Lund RD. Partial preservation of rod and cone ERG function following subretinal injection of ARPE-19 cells in RCS rats. Vis Res 2006; 46: 1459-1472. 